\title{
A STUDY OF CFD SIMULATIONS OF THE FLOW PATTERN IN AN AGITATED SYSTEM WITH A PITCHED BLADE WORN TURBINE
}

\author{
Jan Skočilas*, Ivan Fořt, Tomáš Jirout \\ Czech Technical University in Prague, Faculty of Mechanical Engineering, Department of Process \\ Engineering, Technicka 4, Prague, Czech Republic
}

\begin{abstract}
This paper presents a numerical analysis of an agitated fully baffled cylindrical vessel with a down pumping four blade worn or unworn pitched blade impeller $\left(\alpha=45^{\circ}\right.$ and $\left.30^{\circ}\right)$ under a turbulent flow regime. CFD simulations predict the pumping capacity of the system equipped by worn and unworn pitched blade impeller. Experimental data were taken from the authors' previous work and compared with results of numerical computations. A good agreement with experimental data was obtained. The ensemble-average mean velocity field with worn and unworn impellers was computed. It follows from the simulation results that the wear rate of the impeller blade has a significantly negative effect on the velocity distribution in an agitated liquid. The greater the destruction of the worn blade, the higher is the deformation of the velocity field around the rotating impeller, with a simultaneous decrease in impeller pumping capacity.
\end{abstract}

Keywords: pitched blade impeller, erosion wear, ensemble-average mean velocity, impeller pumping capacity, CFD simulation

\section{INTRODUCTION}

In all areas of technology where solid particles are handled, structures that come into contact with particles exhibit wear. In some applications this wear may be so severe as to limit the life of a component or plant (Fořt and Jirout, 2011), while in others it may be negligible (Hutchings, 1987).

The goal of this work is to describe the agitated fully baffled cylindrical vessel with a down pumping four blade worn or unworn pitched blade impellers by CFD model. Numerical computations will be designed to predict the pumping capacity in comparison with experimental data. The experimental results were obtained from previous work of the authors and will be briefly described with respect to their reference. Given a good agreement of the numerical results, the ensemble-average mean velocity field with worn and unworn impellers will be computed and analysed. Then the model will be verified by the experimental results of the unworn blade impeller agitated system, and applied to the worn blade impellers set-up.

The erosion wear of impeller blades while mixing a solid-liquid suspension usually has a negative effect on technological operations. The erosion process of a pitched blade impeller caused by particles of higher hardness can be described by means of changes in the shape of the leading edge of the worn blade according to the relation (Fořt et al., 2005)

$$
Y(R)=1-C \exp [k(1-R)]
$$


where $Y$ is a dimensionless transversal coordinate along the width of the blade, and $R$ is a dimensionless longitudinal (radial) coordinate along the radius of the blade,

$$
\begin{gathered}
Y=y(r) / h \\
R=2 r / T
\end{gathered}
$$

when $y$ and $r$ are the dimensional coordinates of the worn blade edge presented in Fig. 1 ( $h$ is blade height and $\mathrm{T}$ is vessel diameter).

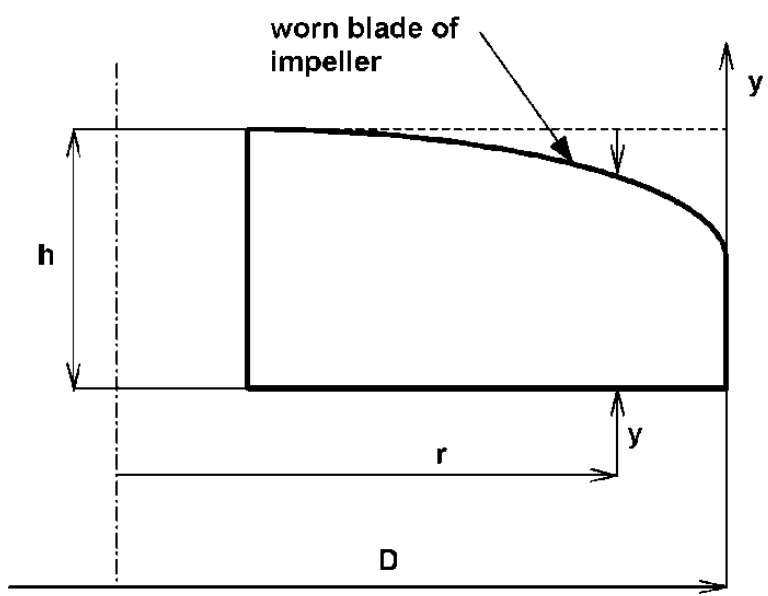

Fig. 1. Radial profile of the leading edge of the worn blade of a pitched blade impeller

The values of the parameters of Eq. (1), the wear rate constant $k$, and the geometric parameter of the worn blade $C$ depend on the impeller pitch angle $\alpha$, on the physico-chemical properties of the solidliquid suspension, and on time $t$. These parameters should be calculated from the experimentally determined profile of the worn blade under given conditions in an agitated charge (Fořt et al., 2005).

\section{MATERIALS AND METHODS}

Measurements of the wear rate of impeller blades were carried out in a pilot plant mixing vessel made from stainless steel (see Fig. 2), with water as the working liquid (density $\rho_{l}=1000 \mathrm{~kg} \mathrm{~m}^{-3}$, dynamic viscosity $\mu=1 \mathrm{mPa} \mathrm{s}$ ) and corundum particles (mean volumetric particle diameter $d_{p}=0.21 \mathrm{~mm}$ and mean volumetric particle concentration of $x_{V}=5 \%$ ). Measurements were carried out by the authors and were already published (see Fořt et al., 2011). The impeller speed was held constant $n=300 \mathrm{~min}^{-1}$ within accuracy $\pm 1 \%$ corresponding to complete homogeneity of the suspension under a turbulent flow regime for an agitated batch. Preliminary experiments made visually in a Perspex mixing vessel under the same conditions as those for the erosion wear experiments showed that there was $90 \%$ homogeneity of the suspension at the impeller speed $n=300 \mathrm{~min}^{-1}$.

During the experiments, the shape of the blade profile was determined from magnified copies of the worn impeller blades (see Fig. 4), scanned to a PC. The parameters of the blade profile for the given time of the erosion process were determined from each curve of four individual worn impeller blades. The selected time interval from the very beginning of each experiment was not to go beyond the moment when the impeller diameter began to shorten. Then the values of the parameters of Eq. (1) - the wear rate constant $k$ and the geometric parameter of the worn blade $C$ - were calculated by the least squares method from the experimentally found profile of each worn blade at the given time interval $t$ of the erosion process. Each curve regression coefficient was better than $R_{c}=0.970$. The resulting values for parameters $k$ and $C$ were the average values calculated from all individual values of these parameters for each blade and their values are presented in Tables 1 and 2. It can be mentioned 
that the chosen shape of the regression curve $Y=f(R)$ fits the experimental data better than the possible two-parameter equations. The determined parameters $k$ and $C$ are presented in the Tables 1 and 2. Parameter $k$ is constant for constant angle of pitched blade and is presented in the title of each table, whereas the parameter $C$ depends on the time of erosion and its values are also different for each of investigated impellers (with different angle of pitched blade).

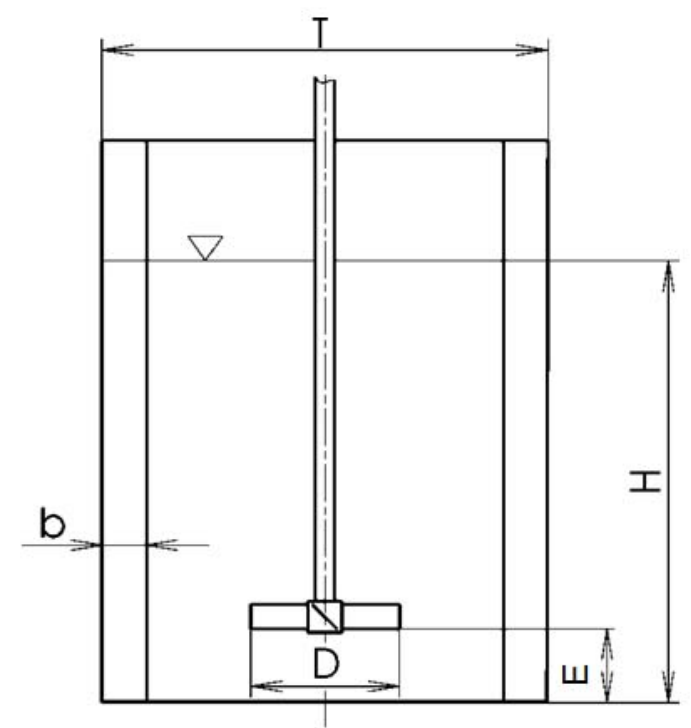

Fig. 2. Pilot plant cylindrical vessel with a down pumping pitched blade impeller;

$$
T=100 \mathrm{~mm}, H / T=1, E / D=1, b / T=1 / 10 \text {, four baffles, } n=300 \mathrm{~min}^{-1}
$$

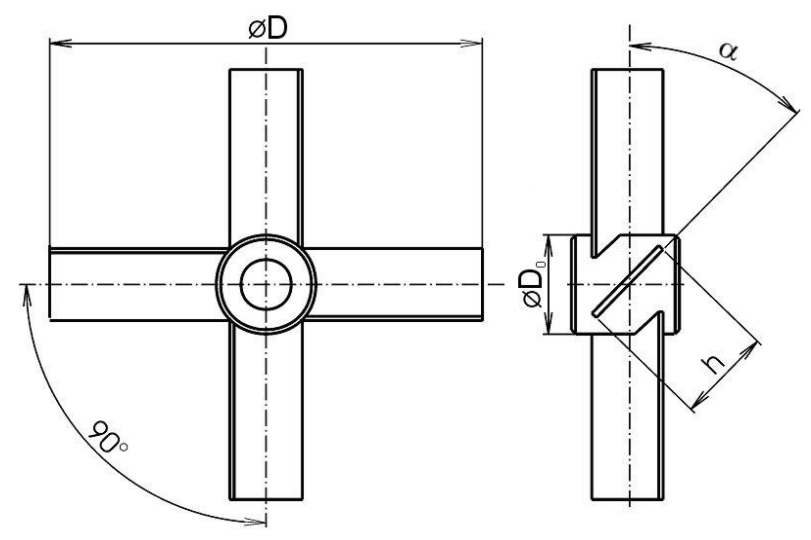

Fig. 3. Four blade pitched blade impeller; $\alpha=45^{\circ}, \mathrm{h} / \mathrm{D}=1 / 5$

\subsection{CDF simulation}

This paper deals with a CFD simulation of the velocity field in agitated liquid water in a fully baffled cylindrical system, see Fig. 2, with a down pumping four blade pitched blade impeller, see Fig. 3, under a turbulent flow regime. The geometry of the stirred tank was generated by $\mathrm{CAD} / \mathrm{CAM}$ software according to the experimental apparatus. The worn leading edge of the impeller blade was modified for the appropriate erosion time, using Equation (1). Four worn blades and the initially unworn blades were modeled by the $\mathrm{CAD} / \mathrm{CAM}$ system and included in a geometric model of a stirred tank.

The Gambit 2.4 preprocessor was applied to assemble the mesh. Special care was paid to selecting the density of the computational grid (a combination of tetrahedral and hexahedral cells) in the vicinity of the curved leading edge of the pitched blade. The tetrahedral elements surrounded only the impeller, 
while the rest of the volume of the model was filled by hexahedral cells. The dependency of the convergence sensitivity on the grid size was analysed. The optimal model mesh size due to convergence and computation time was found. The number of cells was estimated to be 5E05 only, with good accuracy prediction. The cell quality was also examined. The element equiangle and equisize skew parameters were no greater than 0.5 for fewer than $5 \%$ of the elements.

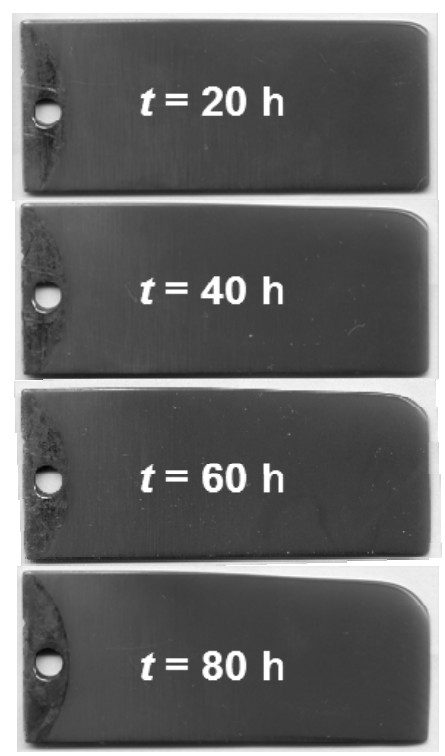

Fig.4. Photographs of worn blades radial profiles for different time of the erosion incidence

Table 1. Main characteristics of CFD computations in the investigated system $(k=-2.90 \pm 0.11, g=0.630)$ for $\alpha=45^{\circ}$

\begin{tabular}{|c|c|c|c|c|}
\hline$t[\mathrm{~h}]$ & $C$ & $N_{Q p, \exp }$ & $N_{Q p, \text { comp }}$ & $R_{\max , z}$ \\
\hline 0 & 0 & 0.850 & 0.820 & 0.227 \\
\hline 40 & 0.116 & 0.816 & 0.790 & 0.240 \\
\hline 60 & 0.174 & 0.798 & 0.782 & 0.233 \\
\hline 80 & 0.232 & 0.781 & 0.759 & 0.253 \\
\hline 100 & 0.290 & 0.763 & 0.754 & 0.247 \\
\hline
\end{tabular}

Table 2. Main characteristics of CFD computations in the investigated system $(k=-4.33 \pm 0.20, g=0.667)$ for $\alpha=30^{\circ}$

\begin{tabular}{|c|c|c|c|c|}
\hline$t[\mathrm{~h}]$ & $C$ & $N_{Q p, \exp }$ & $N_{Q p, \text { comp }}$ & $R_{\max , z}$ \\
\hline 0 & 0 & 0.638 & 0.630 & 0.363 \\
\hline 40 & 0.132 & 0.601 & 0.610 & 0.360 \\
\hline 60 & 0.198 & 0.583 & 0.597 & 0.358 \\
\hline 84 & 0.277 & 0.561 & 0.582 & 0.360 \\
\hline
\end{tabular}

The Reynolds stress simulation for the steady-state Multiple Reference Frame (MRF) approach was used with the standard wall function in the pilot plant mixing vessel (diameter $D=300 \mathrm{~mm}$ ) (Joshi et al., 2011). The other turbulence models were also examined and consequently not used for final computation because of their worse agreement with the experimental results. 
The recommended ratios for the dimensions of the rotating reference frame for an agitated vessel correspond to the impeller blade height and to the diameters of the vessel and the impeller. The height of the MRF is about 2.5 times the blade height (Oshinowoi et al., 2000), and the MRF diameter is equal to the median diameter between the blade tip and the baffle inner edge (Coronero et al., 2011). The MRF model with commonly used turbulence model is suitable for simulating flow parameters of velocity field near the impellers (Harvey et al., 1995). The first order upwind, the second order upwind and the high order QUICK scheme were applied to discretise the convective terms. A numerical solution of the flow equation was achieved by a finite - volume method in the realm of the FLUENT 6.3 general purpose CFD code (Fluent, 2008).

Tables 1 and 2 present the constant $C$ and the pumping capacity $N_{Q P}$ dependency on the time of the erosion incidence $t$. The time when corundum particles were acting on the impeller blade during system mixing was investigated for a specified time interval within 20 and 100 hours. The shape of the worn blade is defined by constant $C$ for respective time. The comparison of the pumping capacity of impeller defined by Equations (4) and (5), i.e. $N_{Q P, \exp }$, and that obtained from CFD simulations $N_{Q P, \text { comp }}$ can be seen in Tables 1 and 2. The last parameter presented in the Tables 1 and 2 represents the maximum velocity radii $R_{\max , z}$ in the cross section below the impeller (see Fig. 10).

The pumping capacity of the pitched blade impeller was calculated from Eq. (4) for an unworn impeller and from Eq. (5) for a worn impeller (Fořt and Jirout, 2011):

$$
\begin{gathered}
N_{Q p, \exp }=\frac{\pi^{2} g^{2}}{2}\left[\sin 2 \alpha\left(\frac{1}{2}-\frac{g}{3}\right)+2 K \sin ^{3} \alpha\right] \\
N_{Q p, \exp }=\frac{\pi^{2} g^{2}}{2}\left(\sin 2 \alpha\left\{\frac{1}{2}\left[1+\frac{c}{k}(1-\exp [k(1-g)])\right]-\frac{g}{3}\right\}+2 K(1-C) \sin ^{3} \alpha\right)
\end{gathered}
$$

where parameter $g$ depends on the position of the boundary radius (see Fořt et al., 2010), where the radial profile of the mean velocity in the impeller discharge flow reaches its maximum value and can be calculated from experimentally determined impeller discharge stream $Q_{P, \exp }$. The impeller flow rate number $N_{Q P, \text { comp }}$ was evaluated from the computed velocity profiles $\mathrm{w}_{\mathrm{z}}(\mathrm{r})$ in the impeller discharge stream leaving the specified cylindrical volume closely surrounding the rotating impeller. The values of the impeller pumping capacities were selected to be reference values for the comparison of the CFD simulation with respect to the results of the experiments. It is worth mentioning, that the pumping capacity of impeller is a commonly used parameter for comparison of experimental data and CFD simulations by many authors (Joshi et al., 2011).

The ensemble-averaged mean time flow field was calculated for both unworn and worn impellers, where the parameters of Eq. (1) were taken from the experimental data (Fořt and Jirout, 2011; Fořt, 1986), see Tables 1 and 2.

\section{RESULTS AND DISCUSSION}

The CFD computation results express the velocity field in a stirred tank with an unworn or worn impellers. Changes in the velocity profiles due to the rate of blade wear were investigated. A comparison of the velocity fields presented in a vertical cross section for an unworn impeller (left side of the figure) and for a maximally worn impeller (100 hours of abrasive particle action on blades $\alpha=45^{\circ}$ and 84 hours on blades $\alpha=30^{\circ}$, right side of the figure) is presented in Fig. 5 for pitch angle $\alpha=45^{\circ}$ and Fig. 6 for $\alpha=30^{\circ}$. 


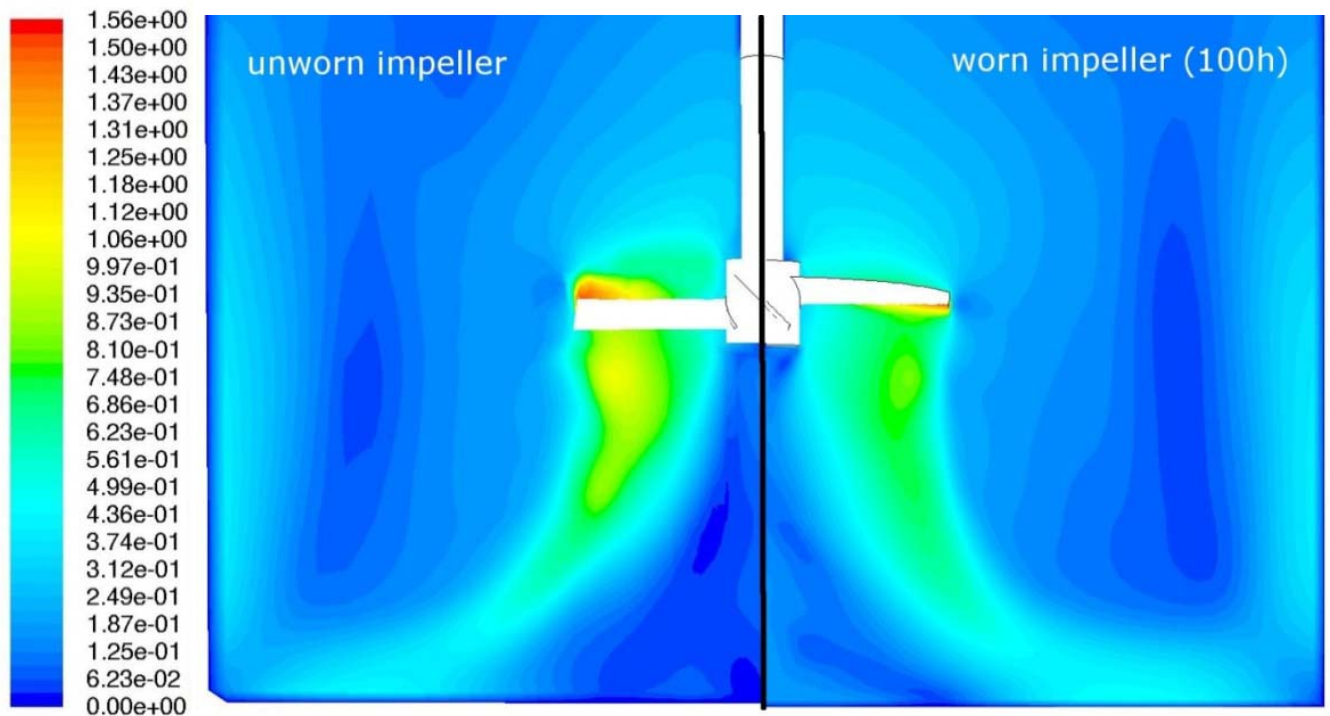

Fig.5. Comparison of the mean velocity fields in a system with unworn and maximally worn down pumping pitched blade impellers (erosion exposition 100 hours) $\alpha=45^{\circ} ; n=300 \mathrm{~min}^{-1}$, velocities in $[\mathrm{m} / \mathrm{s}$ ]

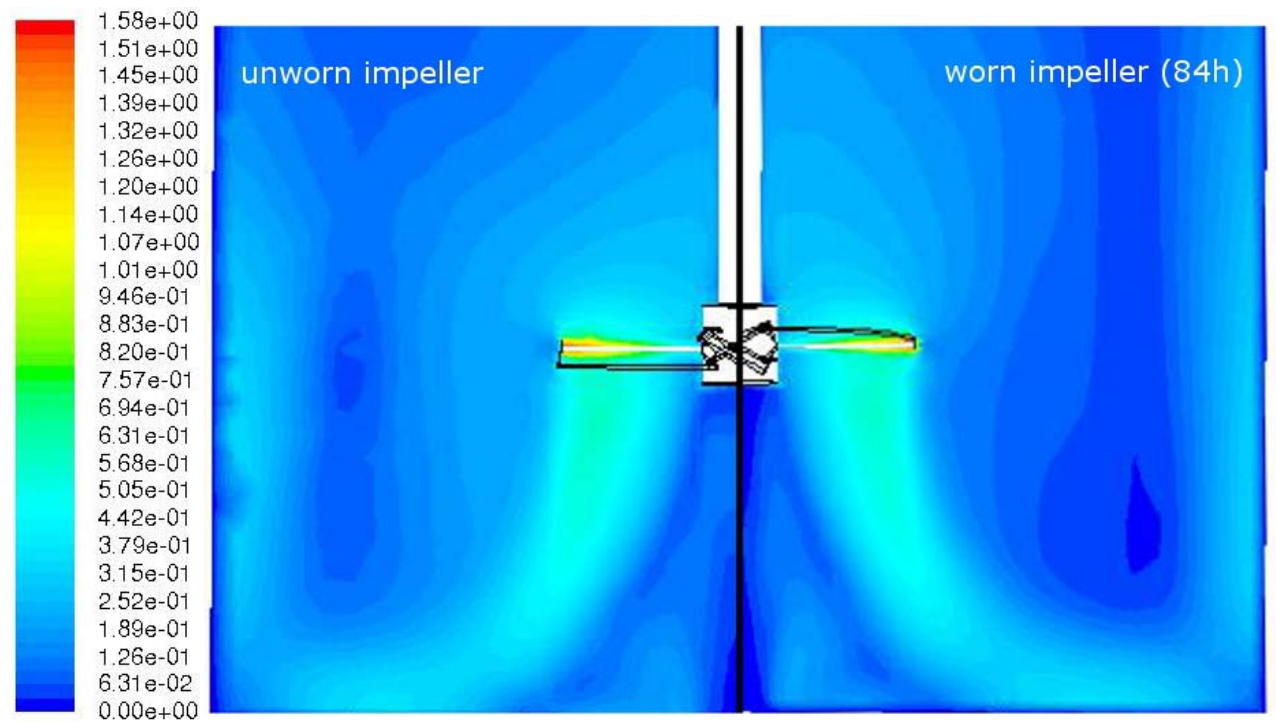

Fig.6. Comparison of the mean velocity fields in a system with unworn and maximally worn down pumping pitched blade impellers $(84 \mathrm{~h}) \alpha=30^{\circ} ; n=300 \mathrm{~min}^{-1}$, velocities in $[\mathrm{m} / \mathrm{s}]$

Only the lower part of the vessel is shown in these figures consisting of the rotating impeller, because a high rate of the energy dissipation occurs in this region and the velocity filed is mostly deformed by the worn blade of the impeller compared to the unworn blade. The white area in the middle represents the shaft, hub and blades of the impeller. The upper half of the worn blade edge is seen on the right side of the figure.

For a system equipped with a pitched blade impeller with $\alpha=45^{\circ}$, the effect of the wear on the velocity field is obvious. The velocity of the fluid passing through the impeller decreases as the wear of the blade edge increases. A stagnation region occurs between the impeller and the vessel wall and it enlarges its volume with an increasing level of the wear process. At the same time the reattachment point in the impeller discharge stream at the bottom of the vessel is shifted towards the axis of symmetry of the stirred tank. 
The impeller pumping capacity was determined by integrating the velocity field on the surface generated below the impeller $(1 \mathrm{~mm}$ in distance from the cylinder circumscribed to the rotating impeller). Then the impeller flow rate number is expressed by

$$
N_{Q_{p}, \text { comp }}=Q_{p, \text { comp }} / n D^{3}
$$

where impeller pumping capacity $Q_{P, \text { comp }}$ can be determined by integrating the axial component of the ensemble-averaged mean velocity $\bar{w}_{z}$ in the impeller discharge stream calculated by means of CFD simulations

$$
Q_{P, \text { comp }}=2 \pi \int_{0}^{D / 2} \bar{w}_{z}(r) r d r
$$

when axial symmetry of this stream is considered.

A comparison between the impeller flow rate number determined by CFD simulation $N_{Q p, c o m p}$ and that determined experimentally $N_{Q p \text { exp }}$ (Fořt and Jirout, 2011; Fořt, 1986) is presented in Table 1 for pitched angle $\alpha=45^{\circ}$, and in Table 2 for $\alpha=30^{\circ}$. It follows from the tables that the impeller pumping capacity decreases with changes in the impeller blade due to the erosion process for both investigated values of angle $\alpha$. At the same time, we can conclude that the resulting CFD simulation values $N_{Q p \text {,comp }}$ correspond to the experimental data $N_{Q p \text { exp }}$, fairly well.

The ensemble-average mean velocity profiles in dependence on dimensionless radius were investigated in the regions above and below the rotating impeller.

$$
R=\frac{2 r}{T}
$$

The dimensionless velocity was defined for its axial component

$$
W_{z}=\frac{\bar{w}_{z}}{\pi D n}
$$

where $\bar{w}_{z}$ is the ensemble-average mean value of the axial velocity components for a given radius in a stirred tank $r, n$ is impeller speed, $T$ is mixing vessel diameter and $D$ is impeller diameter. The ensemble-average mean velocity was always calculated as an average value of the mean velocity over the appropriate circle radius.

The radial profiles of the axial ensemble-average mean velocity above and below the impeller are presented, see Figs. 7 and 9 for $\alpha=45^{\circ}$, and Figs. 8 and 10 for $\alpha=30^{\circ}$. The velocity field deformation is obvious from the figures, especially in the system equipped with an impeller with $\alpha=45^{\circ}$. The maximum velocity decreases with increasing blade wear, and the profiles become flat. Meanwhile, the deformations of the velocity field and investigated profiles are not so significant in the system equipped with an impeller with $\alpha=30^{\circ}$.

In comparison with the system equipped with a pitched blade impeller $\left(\alpha=45^{\circ}\right)$, no significant effect of blade wear on the velocity field can be seen in the system with a pitched blade impeller with $\left(\alpha=30^{\circ}\right)$. The worn impeller discharge stream is narrower than the one leaving the unworn impeller. A stagnation region also occurs between the impeller and the vessel wall. It enlarges its volume with an increasing rate of the worn impeller, and it reduces the velocity magnitude in the center of its volume. The discharge stream of the impeller with $\alpha=30^{\circ}$ is slower (its velocity magnitude is lower) than the discharge stream of the impeller with $\alpha=45^{\circ}$, compare Figs. 5 and 6 or Figs. 9 and 10. 


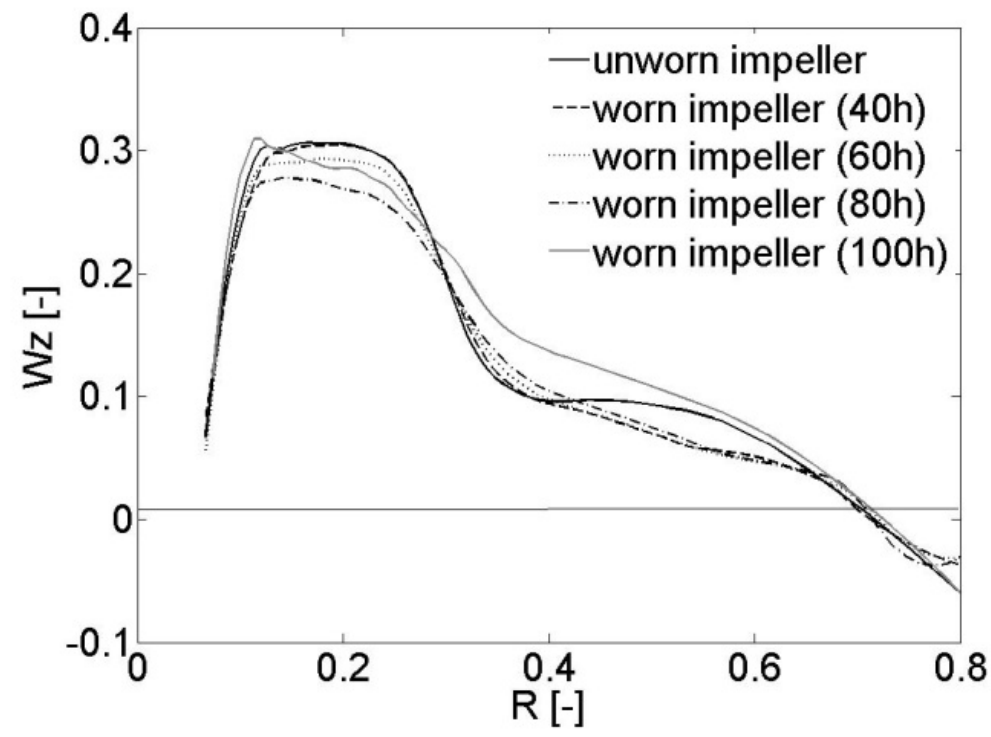

Fig.7. Axial component of the ensemble-averaged mean velocity in the cross section above impeller, $\alpha=45^{\circ}$

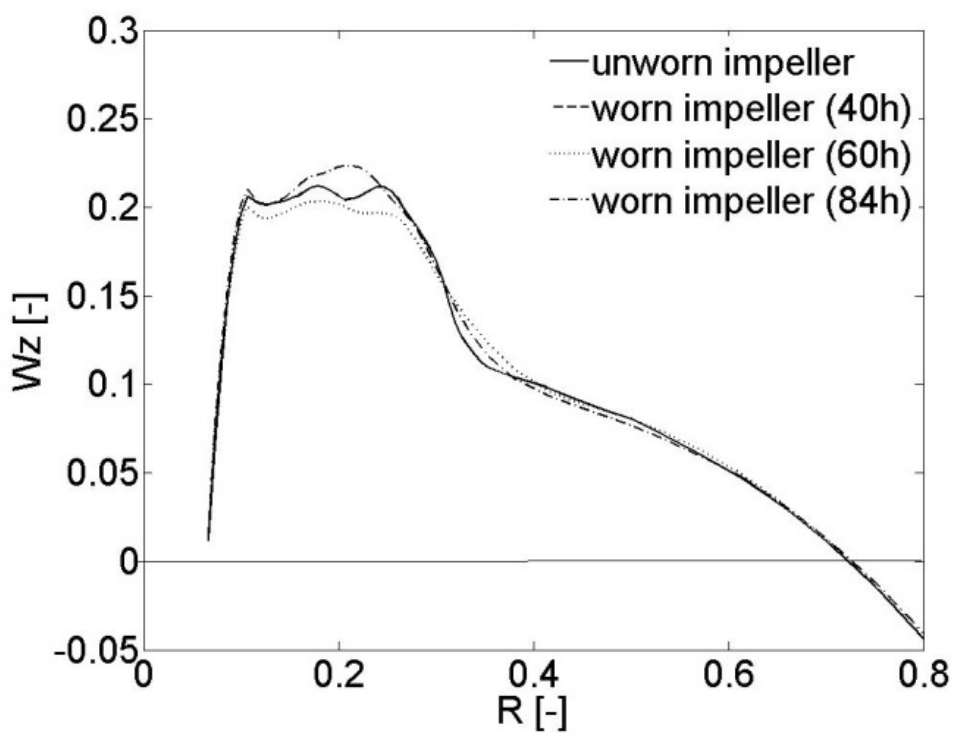

Fig.8. Axial component of the ensemble-averaged mean velocity in the cross section above the impeller, $\alpha=30^{\circ}$

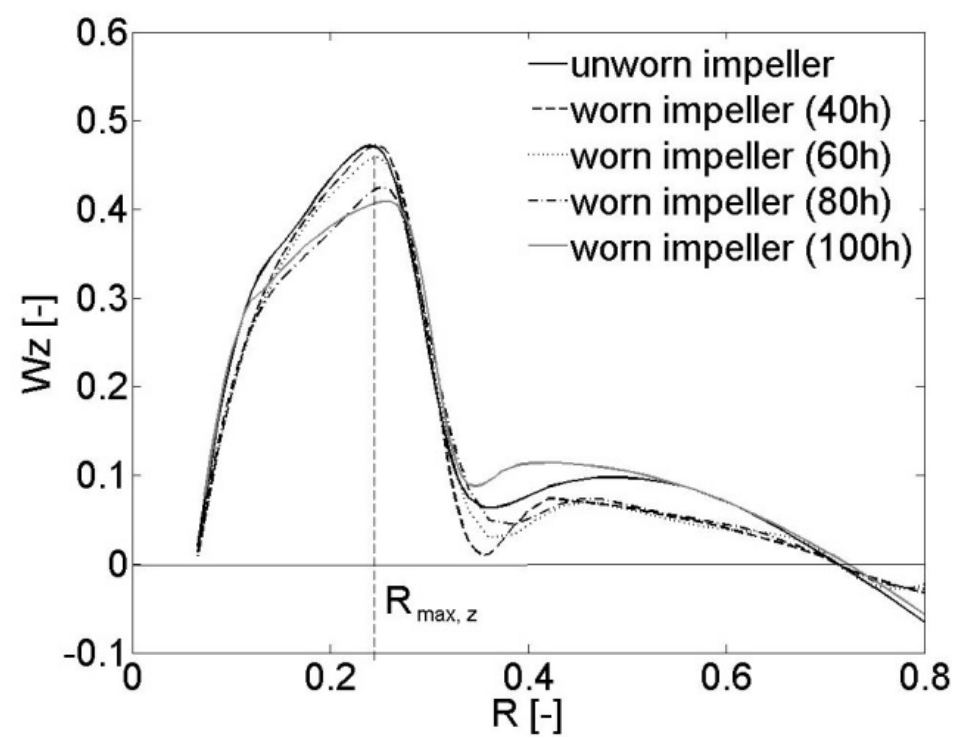

Fig.9. Axial component of the ensemble-averaged mean velocity at the cross section below impeller, $\alpha=45^{\circ}$ 


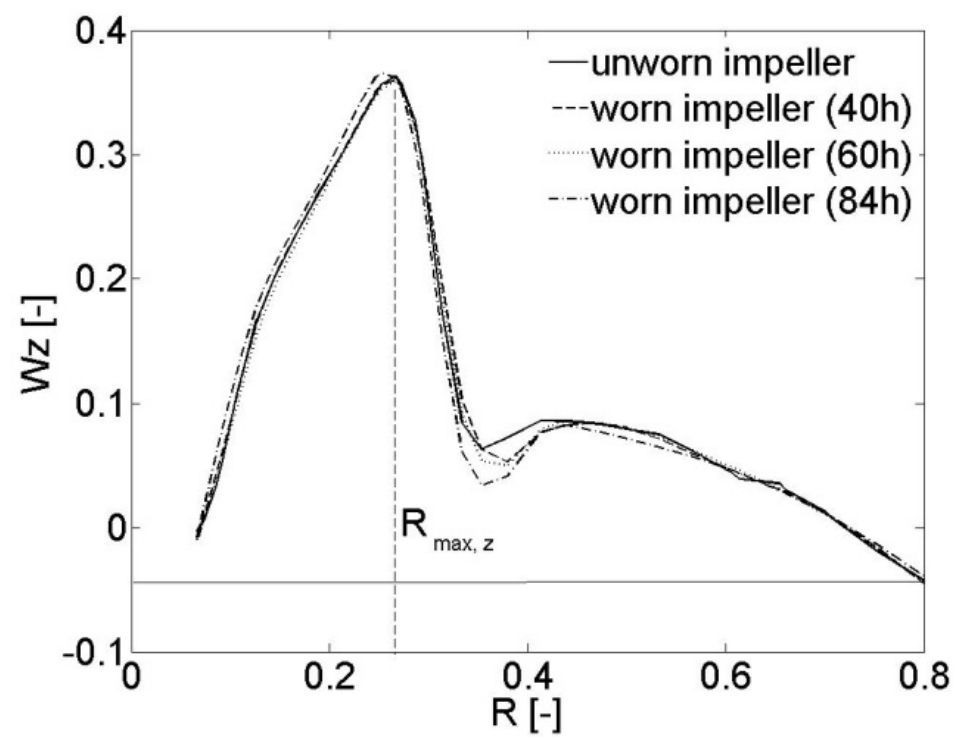

Fig.10. Axial component of the ensemble-averaged mean velocity at the cross section below impeller, $\alpha=30^{\circ}$

The maximum velocity radii $R_{\max , z}$ in the cross section below the impeller were determined from the computed data presented in Figs. 9 and 10 for various wear rates. The values of these radii are reported in Tables 1 and 2. A slight shift of the maximum velocity position from the impeller rotation axis of symmetry is observed. Finally, it follows from our results that the radial profiles of the axial ensembleaverage mean velocity above and below the impeller exhibit an upstream flow in the vicinity of stirred tank wall, which is well known from experimental results (Fořt, 1986).

\section{CONCLUSIONS}

It follows from the results of the CFD simulations and also from our own previous experimental work that the wear rate of an impeller blade has a significantly negative effect on the mean velocity field in an agitated liquid. The greater the destruction of the worn blade, the higher the deformation of the velocity field below the rotating impeller, with a simultaneous decrease in the ensemble-averaged mean velocity in the impeller discharge stream. The model was successfully verified by experimental results for both worn and unworn pitched blade impellers. The shape of the axial component of the ensembleaveraged mean velocity in the cross section above and below the unworn blade impeller and the position (radius) of the maximum value of velocity in the profile are in good agreement with our own experimental results of the investigated stirred system even with other authors.

Deformations of the velocity field were confirmed experimentally in our own previous work, and have been confirmed in the conducted CFD simulations. The measured impeller pumping capacity agrees well with the pumping capacity predicted by a finite volume model. The CFD model and computation procedure are considered to be sufficient for a description of an agitated system with worn and unworn impellers with a specified geometry. Moreover, the radii corresponding to the maximal axial velocity components in the impeller discharge stream are shifted (especially for the impeller with pitched blade angle $45^{\circ}$ ) from the symmetry axis of impeller rotation to the wall of the stirred tank. The observed radius displacement of the maximal axial velocity is caused by blade wear. This result was confirmed by both experiments and simulations.

The authors of this paper appreciate financial support from the Czech Ministry of Education (Grant No. MSM6840770035). 


\section{SYMBOLS}

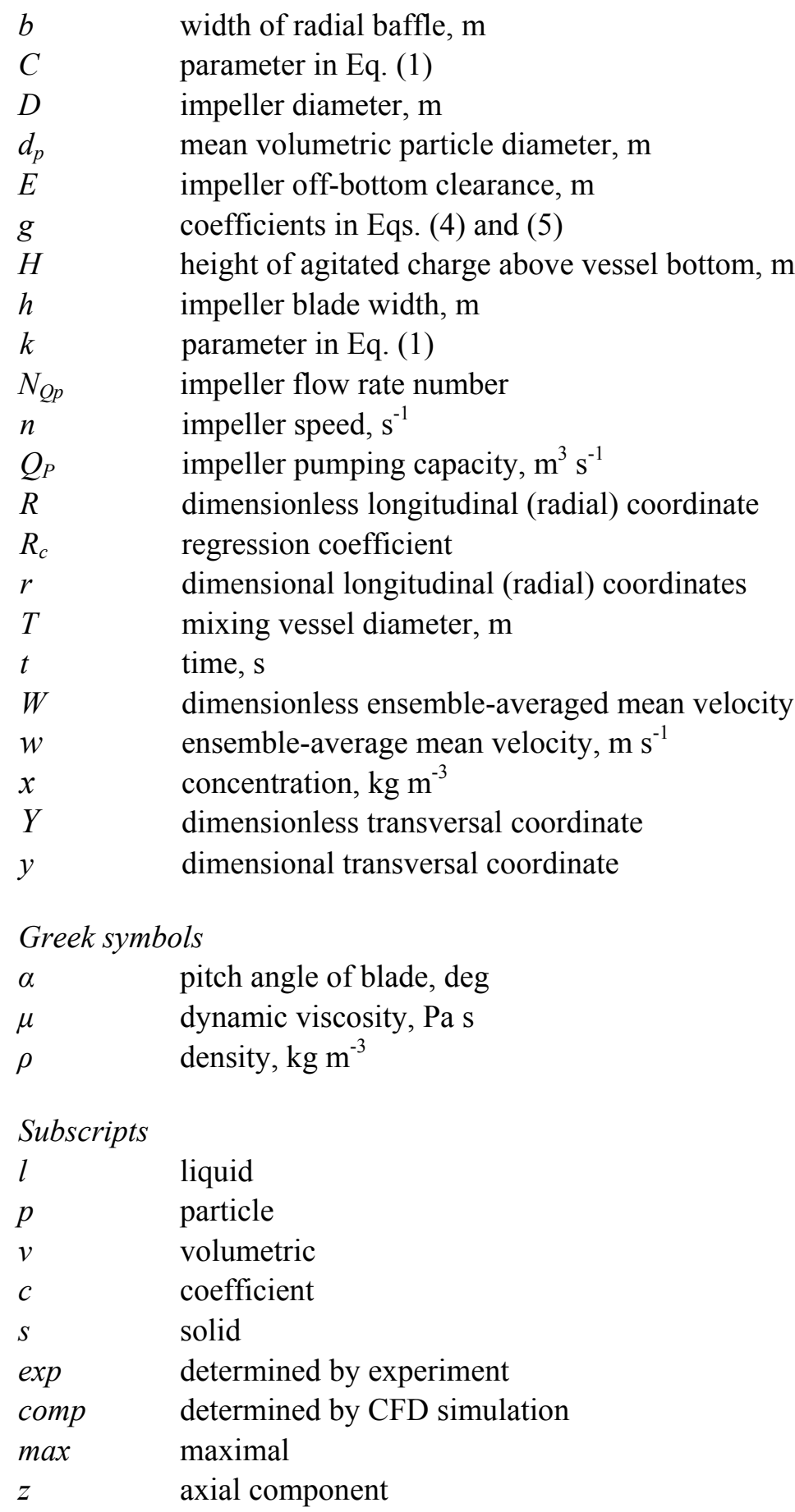

\section{REFERENCES}

Coronero M., Montante G., Paglianti A., Magelli F., 2011. CFD prediction of fluid flow and mixing in stirred tanks: Numerical issues about the RANS simulations. Comp. Chem. Eng., 35, 1959-1968. DOI: 10.1016/j.compchemeng.2010.12.007.

Harvey A.D., Lee C.K., Rogers S.E., 1995. Steady-state modeling and experimental measurement of a baffled impeller stirred tank. AIChE Journal, 41, 2177-2186. DOI: 10.1002/aic.690411002.

Fluent Inc., 2008. FLUENT 6.3 User's Guide.

Fořt I., 1986. Flow and turbulence in vessels with axial impellers, in: Uhl V.W., Gray J.B. (Eds.), Mixing, Theory and Practice, Vol. III. Academic Press, New York, 133-197. 
Fořt I., Jirout T., Cejp J., Čuprová D., Rieger F., 2005. Study of erosion wear of pitched blade impellers in solidliquid suspensions. Chem. Process Eng., 26, 437-450.

Fořt I., Kysela B., Jirout T., 2010. Flow characteristics of axial high-speed impellers. Chem. Process Eng., 31, 661-679.

Fořt I., Jirout T., 2011. The relation between the rate of erosion wear of a pitched blade impeller and its process characteristics. Chem. Eng. Res. Des., 89, 1929-1937. DOI: 10.1016/j.cherd.2011.01.024.

Hutchings I.M., 1987. Wear by particulates. Chem. Eng. Sci., 42, 869-878. DOI: 10.1016/0009-2509(87)80045-3.

Joshi J.B., Nere N.K., Rane Ch.V., Murthy B.N, Mathpati Ch.S., Patwardham A.W., Ranade V.V., 2011. CFD simulation of stirred tank: Comparison of turbulent models (Part II: Axial flow impellers, multiple impellers and multiphase dispersion). Can. J. Chem. Eng., 89, 754-816. DOI: 10.1002/cjce.20465.

Oshinowo A., Jaworski Z., Dyster K.N., Marshall E., Nienow A.W., 2000. Predicting the tangential velocity field in stirred tank using Multiple Reference Frames (MRF) model with validation by LDA measurements. Proc. 10th European Conf. on Mixing. Delft, The Netherlands, July 2-5, 2000, 281-288.

Received 04 July 2012

Received in revised form 21 November 2012 Accepted 03 December 2012 